\title{
ARTICLE
}

Received 5 Apr 2016 | Accepted 4 Nov 2016 | Published 15 Dec 2016

DOI: $10.1038 /$ ncomms13848

OPEN

\section{Low-affinity CD4 + T cells are major responders in the primary immune response}

\author{
Ryan J. Martinez ${ }^{1}$, Rakieb Andargachew ${ }^{1}$, Hunter A. Martinez ${ }^{1} \&$ Brian D. Evavold ${ }^{1}$
}

A robust primary immune response has been correlated with the precursor number of antigen-specific T cells, as identified using peptide $\mathrm{MHCll}$ tetramers. However, these tetramers identify only the highest-affinity $\mathrm{T}$ cells. Here we show the entire CD4+ T-cell repertoire, inclusive of low-affinity T cells missed by tetramers, using a T-cell receptor (TCR) signalling reporter and micropipette assay to quantify naive precursors and expanded populations. In vivo limiting dilution assays reveal hundreds more precursor $\mathrm{T}$ cells than previously thought, with higher-affinity tetramer-positive T cells, comprising only 5-30\% of the total antigen-specific naive repertoire. Lower-affinity T cells maintain their predominance as the primary immune response progresses, with no enhancement of survival of T cells with high-affinity TCRs. These findings demonstrate that affinity for antigen does not control CD4 + T-cell entry into the primary immune response, as a diverse range in affinity is maintained from precursor through peak of T-cell expansion.

\footnotetext{
${ }^{1}$ Department of Microbiology and Immunology, Emory University, 1510 Clifton Rd NE, Atlanta Georgia, 30322, USA. Correspondence and requests for materials should be addressed to B.D.E. (email: bevavol@emory.edu).
} 
T he number of antigen-specific $\mathrm{CD} 4+\mathrm{T}$ cells in the naive mouse correlates with the effector potential of the population. Defining the total number of antigen-specific $\mathrm{T}$ cells in an organism, therefore has important ramifications for understanding immune response outcomes ${ }^{1-6}$. Currently, peptide-major histocompatibility complex (pMHC) tetramers (Tet) provide the gold standard for the identification of antigenspecific $\mathrm{CD} 4+\mathrm{T}$ cells ${ }^{7,8}$. Tetramers are limited to identifying $\mathrm{CD} 4+\mathrm{T}$ cells with higher-affinity T-cell receptor (TCR):pMHC interactions $s^{9-12}$ and bind via an avidity-dependent mechanism without dependence on $\mathrm{CD} 4$ co-receptor ${ }^{11,13-18}$. Thus, unbiased assessment of the total number of antigen-specific $\mathrm{T}$ cells has been challenging in the case of $\mathrm{CD} 4+\mathrm{T}$ cells, owing to the highaffinity predisposition by tetramers. Therefore, the contribution of lower-affinity $\mathrm{T}$ cells in the naive and expanded T-cell repertoires is currently unknown, in part due to the difficulty of accurately quantifying these $\mathrm{T}$ cells in the naive repertoire.

Previous studies have suggested $\mathrm{T}$ cells with higher-affinity TCR:pMHC interactions possess enhanced survival or preferred selection during the primary or secondary immune response ${ }^{19-21}$, with others reporting affinity independence of T-cell maintenance during an immune response ${ }^{22}$. These experiments only analysed biased populations by restricting $\alpha \beta$ TCR diversity and/or sampling with pMHC tetramers, thereby potentially missing clones participating in the response. Further works using TCR-transgenic ( $\mathrm{Tg}$ ) models and altered peptide ligands support the concept that optimal responses occur in the case of highest-affinity interactions ${ }^{23,24}$. Yet, none of these analyses encompass the full polyclonal repertoire, leaving the question on the contribution of lower-affinity and higher-affinity $\mathrm{T}$ cells in the expanded T-cell population unanswered.

To study the contribution of low-affinity and high-affinity $\mathrm{CD} 4+\mathrm{T}$ cells to the primary immune response, the number of naive and expanded total $\mathrm{T}$ cells must be identified. Multiple groups have acknowleged the presence of lower-affinity (Tet-negative, Tet-) $\mathrm{T}$ cells, but these cells are difficult to adequately quantitate at any point during the immune response $^{9,11,25}$. To accomplish this task, we repurposed the Nur77 ffp TCR signalling reporter as a method for identifying lower-affinity, Tet - antigen-specific $\mathrm{CD} 4+\mathrm{T}$ cells. To define the number of precursor $\mathrm{T}$ cells, we used the Nur77 ${ }^{\text {gfp }}$ reporter in an in vivo limiting dilution assay (LDA), finding Tet - CD4+ $\mathrm{T}$ cells made up the majority of the naive antigen-specific T-cell population. On expansion, the ratio of high-affinity to low-affinity antigen-specific $\mathrm{CD} 4+\mathrm{T}$ cells was reduced, signifying high-affinity TCRs do not confer a clonal expansion advantage. As well, total naive precursor numbers positively correlate with expanded CD4 $+\mathrm{T}$ cells, indicating total precursor number predicts expansion when the entire range of TCR affinity is analysed. These data demonstrate T-cell responses are population based with a range of naive affinities that are maintained throughout an immune response to preserve affinity and diversity.

\section{Results}

LDA reveals similar numbers of Tet - and Tet $+\mathrm{CD} 4+\mathrm{T}$ cells. The transfer of bulk $\mathrm{CD} 4+\mathrm{T}$ cells at the tetramer-positive $($ Tet +$)$ limiting dilution level has proven fruitful in the study of single-cell expansion and differentiation ${ }^{26,27}$. However, polyclonal antigen-specific $\mathrm{CD} 4+\mathrm{T}$ cells with lower-affinity TCR:pMHCII interactions are not detected by traditional pMHCII tetramer staining used in these assays $9,10,28$. Consequently, lower-affinity, antigen-specific CD4 $+\mathrm{T}$ cells are missed in these single-clonotype pMHCII tetramerbased analyses. To better define the response inclusive of lower-affinity $\mathrm{T}$ cells, the TCR-specific signalling reporter Nur77 was used as a readout of antigen specificity ${ }^{29-31}$. To determine the extent that lower-affinity $\mathrm{T}$ cells participate in an immune response, we transferred $\mathrm{T}$ cells from Nur77ffp mice at the levels reported to be limiting for Tet + LCMV GP $66-77^{-}$ specific CD4 $+\mathrm{T}$ cells $\left(6 \times 10^{6} \mathrm{CD} 4+\right.$ Thy $1.2+\mathrm{T}$ cells into congenically distinct Thyl.1 + recipients $)^{26}$. At day 7 post immune challenge with peptide antigen in Complete Freund's adjuvant (CFA) (GP66/CFA; Fig. 1a), GP66-Tet + CD4 + T cells were enriched and designated as donor (Thy1.2+) or host $($ Thyl.1+) derived based on their respective Thyl expression (Fig. 1b, gating strategy Supplementary Fig. 1A). At this number of transferred T cells, four of the seven mice possessed a GP66Tet + donor clone, in close agreement with published results ${ }^{26}$. To identify if these mice also contained lower-affinity Tet - cells, the samples were depleted of GP66-Tet $+\mathrm{T}$ cells by tetramer pulldown, and the remaining $\mathrm{T}$ cells (Fig. 1c) were stimulated in vitro for $18-24 \mathrm{~h}$ with specific $\left(\mathrm{GP}_{61-81}\right)$ or non-specific peptide antigen $\left(\operatorname{Aasf}_{24-32}, \mathrm{MOG}_{35-55}, \mathrm{NP}_{311-325}\right.$; Fig. 1a). To assess antigen specificity, the nuclear receptor Nur77 was used as its expression has been shown to be TCR signalling strength dependen ${ }^{29}$. On the basis of Nur77 expression, six of the seventransferred Tet $-\mathrm{CD} 4+$ T-cell populations stimulated with GP66 demonstrated Nur77/CD69 expression with a greater than three s.d. increase above the mean of the non-specific controls (Fig. 1d). There was a low-level background of Nur77 expression that was priming antigen independent (Fig. 1d), but the normalized per cent increase of Nur77/CD69 expression for the GP66-stimulated samples caused the greatest increase. These findings show lower-affinity, Tet - populations are present at least as frequent as Tet + cells, as demonstrated by similar number of mice with antigen-specific populations (4/7 mice for Tet,+ 6/7 mice for Tet - ).

Nur77 expression has been used to readout functionality of $\mathrm{CD} 4+\mathrm{T}$ cells in multiple systems ${ }^{29-35}$. Even though these T cells are functional, it does not describe the role these $\mathrm{T}$ cells are playing in the immune response. Therefore, we interrogated the expression of Bcl-6, the lineage-defining transcription factor for follicular helper $\mathrm{T}$ cells $\left(\mathrm{T}_{\mathrm{FH}}\right)$, in the Tet + and Tet - antigenspecific T cells. Bcl-6 expression has been reported to be induced with a variety a range of affinity, with the highest-affinity and lowest-affinity interactions, inducing $\mathrm{Bcl}-6 / \mathrm{T}_{\mathrm{FH}}$ development ${ }^{36}$. Antigen-specific T cells showed expression of Bcl-6, regardless of whether they were Tet + or Tet - , although a greater frequency of higher-affinity, Tet $+\mathrm{T}$ cells expressed Bcl-6 compared with lower-affinity, Tet - antigen-specific $\mathrm{T}$ cells (Fig. 1e). Antigeninexperienced $(\mathrm{CD} 44-)$ T cells and antigen-experienced but not antigen-specific (CD44 + Nur77 - ) T cells demonstrated little to no expression of Bcl-6 (Fig. 1e). Our data support the findings that $\mathrm{T}_{\mathrm{FH}}$ differentiation can occur for TCRs with a range of affinities $^{36,37}$. As well, the data show that high-affinity and lowaffinity $\mathrm{T}$ cells have shared, but distinct functions in the total T-cell population.

Low-affinity $\mathrm{T}$ cells predominate the naive repertoire. Although the above data identified Tet $-\mathrm{CD} 4+\mathrm{T}$ cells during an immune response, it did not quantitate the initial precursor number of these lower-affinity $\mathrm{T}$ cells. We next set out to enumerate the precursor frequency of naive antigen-specific $\mathrm{CD} 4+\mathrm{T}$ cells independent of pMHCII tetramer by using the Nur77 reporter in an in vivo $\mathrm{LDA}^{38}$. Varying numbers of $\mathrm{CD} 4+\mathrm{T}$ cells from Nur77gfp mice were transferred into T-cell-deficient TCR $\alpha^{-1-}$ mice and recipients were immunized with peptides emulsified in CFA (Fig. 2a). Lymphopenic hosts were used as this allowed for larger blast sizes for individual T-cell clones, thereby increasing 
a

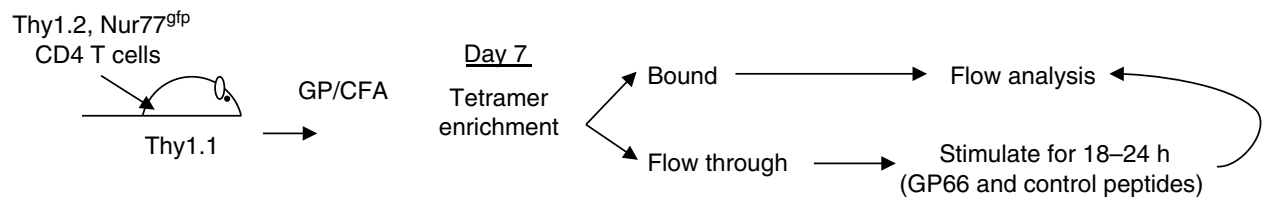

b
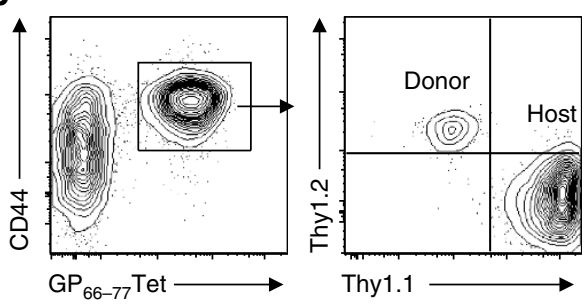

C

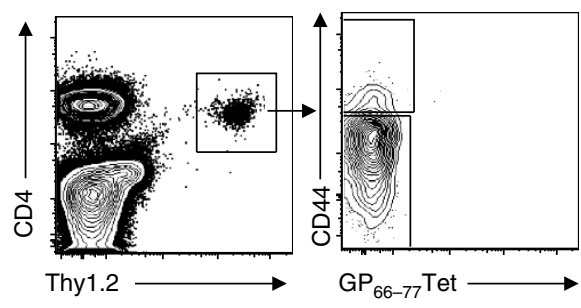

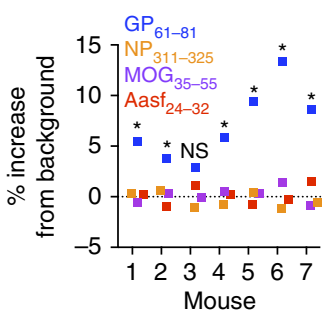

e
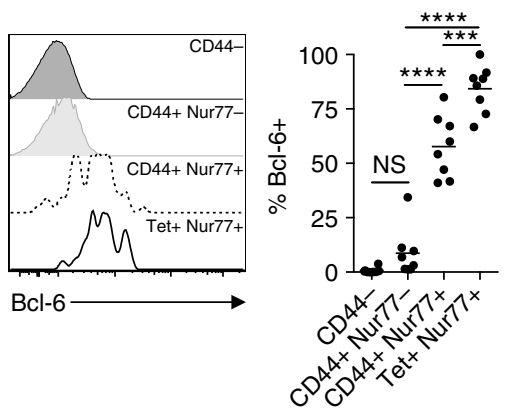

Figure 1 | Tet + LDA reveals low-affinity CD4 $+\mathbf{T}$ cells in the naive repertoire. (a) $6 \times 10^{6}$ Nur77gfp CD4 + T cells $\left(6 \times 10^{5}\right.$ after a $10 \%$ park rate Thy $1.2+$ ) were transferred into congenically distinct (Thy $1.1+$ ) mice and immunized with GP $_{61-81}$ peptide/CFA followed by tetramer enrichment and restimulations. (b) Flow cytometry of representative GP66-Tet + enrichment of secondary lymphoid organs from day 7 immunized mice with a positive donor (Thy1.2+) clone identified. (c) After tetramer enrichment, the unbound cells were independently stimulated with $100 \mu \mathrm{g} \mathrm{ml}{ }^{-1}$ of specific (GP $61-81$ ) or non-specific $\left(\right.$ Aasf $_{24-32}, \mathrm{MOG}_{35-55}$ or $\mathrm{NP}_{311-325}$ ) peptides and gated to identify donor CD44+ Tet - Thy1.2+ CD4 + T cells by flow cytometry. (d) Percent change over averaged background of Nur77gfp + CD69 + CD4 + T cells after stimulation with individual antigens ( $n=7$, two independent experiments, ${ }^{\star}=3$ s.d. above background average, NS = no significance). (e) Bcl- 6 expression measured by flow cytometry of CD4 + T cells from day 5 immunized mice within identified subsets. Frequency of cells expressing $\mathrm{Bcl}-6$ within each subset identified (points represent individual mice, $n=6-7$, two experiments, one-way analysis of variance, $N S=$ no significance, ${ }^{\star \star \star} P<0.001$, ${ }^{\star \star \star \star} P<0.0001$ ).

the sensitivity of the assay as it is dependent on population increases in expression of Nur77. At 21 days post immunization, splenocytes from recipient mice were restimulated ex vivo for 18-24h with specific or non-specific peptide antigens before assessment for Nur77gfp and CD69 expression (Fig. 2b). Representative flow plots of transferred CD4 $+\mathrm{T}$ cells that demonstrated positive responses (top row, Fig. 2b) and negative responses (bottom row, Fig. $2 \mathrm{~b}$ ) are shown for $\mathrm{NP}_{311-325}$-primed mice. $\mathrm{NP}_{311-325}$-stimulated samples containing a Nur77gfp + $\mathrm{CD}{ }^{+}$population greater than three s.d.'s above the mean of two non-specific peptides $\left(\mathrm{GP}_{61-81}\right.$ non-specific peptide control shown) were tabulated as positive and graphed as a function of the number of CD4 $+\mathrm{T}$ cells present in the hosts after transfer (Fig. 2c). The points at which $37 \%$ of the hosts do not possess a clone equates to where a single precursor cells is present in the population (dotted line, Fig. $2 \mathrm{c}$ ) and is based on a $20 \%$ park rate into lymphopenic mice with a total of $4 \times 10^{7} \mathrm{CD} 4+\mathrm{T}$ cells per mouse. The precursor frequencies were calculated for six different epitopes (MOG ${ }_{35-55}$ self-antigen: 1,099 (669-1805) cells, MTB 85b $b_{280-294}: 1,206$ (682-2,133) cells, LCMV GP $61-81$ : 627 (322-1,218) cells, Chlamydia Aasf ${ }_{24-32}: 350$ (169-725) cells, Influenza $\mathrm{NP}_{311-325}$ : 285 (179-454) cells, and Salmonella FliC $_{427-441}$ : 192 (92-402) cells) that were chosen as they spanned the range of previously published tetramer precursor frequencies and were plotted with their 95\% confidence levels (Fig. 2d $)^{8}$. Comparison of the LDA and naive tetramer enrichments revealed Tet + numbers accounted for $5-30 \%$ of the total naive antigen-specific repertoire, demonstrating tetramer only identifies a minor subset of each antigen-specific $\mathrm{T}$ cells in a naive population. Control LDA experiments were performed for $\mathrm{NP}_{311-325}$ antigen in wild-type (WT) mice and in $\mathrm{TCR} \alpha^{-/-}$ mice, when using only $10 \mu \mathrm{g} \mathrm{ml}^{-1}$ of peptide for restimulation, instead of $100 \mathrm{~g} \mathrm{ml}^{-1}$ as for previous LDA experiments, finding similar results across all experiments (Fig. 2e,f, gating strategy Supplementary Fig. 1B for WT). These findings demonstrate Tet $-\mathrm{T}$ cells are present in the naive $\mathrm{T}$-cell repertoire at greater frequencies than Tet $+\mathrm{CD} 4+\mathrm{T}$ cells and proliferate in an antigen-specific manner that could be read out by the Nur77 assay.

Lower-affinity $\mathrm{T}$-cell clonotypes are identified by LDA. To confirm the Nur77gfp + CD4 + T cells identified Tet $-\mathrm{T}$ cells, pMHCII tetramer was used to costain unstimulated LDA samples when calculating precursor numbers (Fig. 3a). Of the 34 mice receiving $\mathrm{T}$ cells for calculating the precursor numbers for $\mathrm{NP}_{311-325}$, only one mouse possessed Tet $+\mathrm{T}$ cells (Fig. 3a, left panel), while 20 mice possessed antigen-specific Nur77gtp + cells and the remaining 13 mice did not respond. Next, the micropipette adhesion frequency assay (MP) was used to determine the affinity of CD4 $+\mathrm{T}$ cells from mice that were either positive or negative for antigen-specific Nur77 upregulation during LDA. 
a

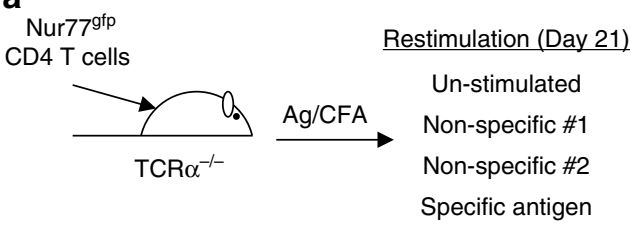

C

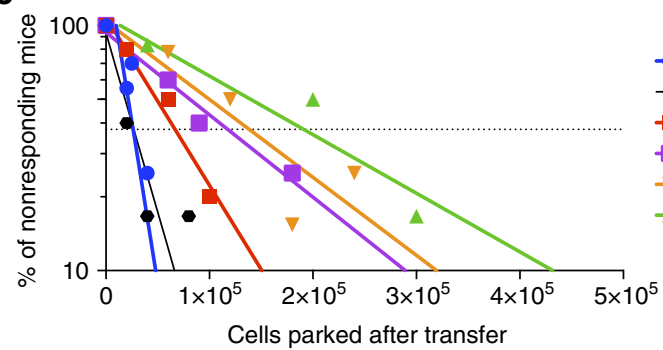

b

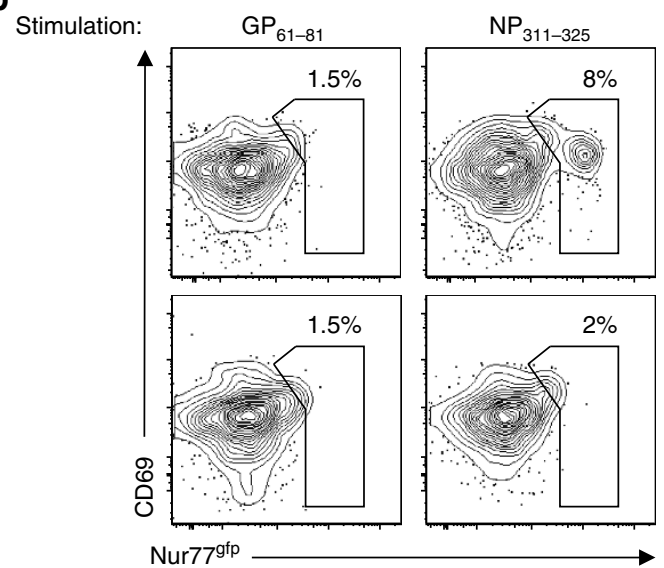

f d

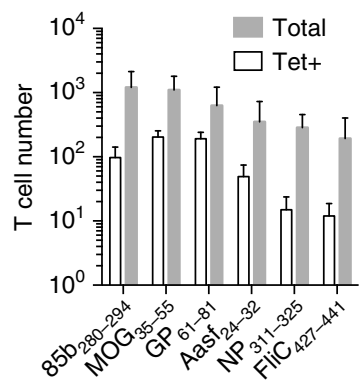

e

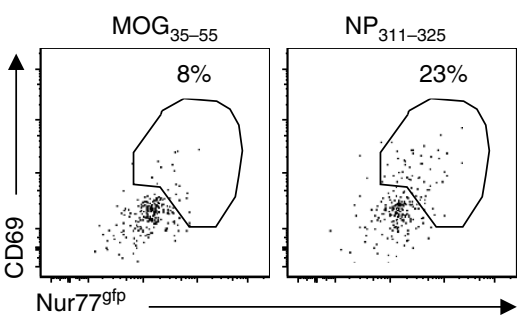

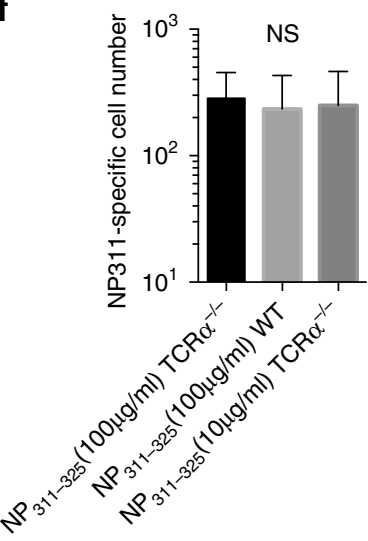

Figure 2 | Increased number of naive precursor identified using an in vivo LDA. (a) Varied numbers of purified Nur77gfp CD4 + T cells were transferred into individual TCR $\alpha^{-/-}$mice, immunized with peptide antigen in CFA and allowed to expand for 21 days before peptide rechallenge. (b) Day 21 flow cytometry analysis of antigen specificity on donor CD4 + T cells after $\mathrm{NP}_{311-325}$ immunization showing CD69/Nur77 expression after antigen rechallenge with either control $\left(\mathrm{GP}_{61-81}\right.$-left panel) or priming antigen $\left(\mathrm{NP}_{311-325}\right.$-right panel). $\mathrm{NP}_{311-325}$-positive clone shown on top row with negative clone shown on bottom row. (c) Positive clones were identified when the antigen-specific upregulation of CD69/Nur77 were three s.d.'s above the background mean and were graphed as a function of initial cells transferred after accounting for a $20 \%$ park rate in lymphophenic mice $(n=4-12$ mice per concentration per antigen). Dotted line represents 37\% mark of nonresponding mice. (d) Tabulated pMHCIl tetramer and Nur77 LDA calculated naive CD4 + T cells number for a single antigen, represented as mean $\pm 95 \%$ confidence interval. FliC and Aasf Tet + values are taken from previously published work (Marc Jenkins, personal communication, Nelson et al. ${ }^{8}$ ). (e) Limiting dilution experiments in WT mice after immunization with $\mathrm{NP}_{311-325} / \mathrm{CFA}$, with flow cytometry plots showing CD69 and Nur77 expression for background $\left(\mathrm{MOG}_{35-55}\right)$ or antigen-specific stimulation $\left(\mathrm{NP}_{311-325}\right.$; representative sample). (f) Enumeration of naive LDA for $\mathrm{NP}_{311-325^{-}}$specific T cells in TCR $\alpha^{-/-}$or WT mice restimulated with $100 \mu \mathrm{g} \mathrm{ml}^{-1}$ of peptide or TCR $\alpha^{-/-}$mice restimulated with $10 \mu \mathrm{g} \mathrm{ml}^{-1}$ peptide (five independent experiments, three to four T-cell dilutions per experiment, data represented as mean $\pm 95 \%$ confidence level, oneway analysis of variance, NS = no significance).

CD4 + T cells from LDA-positive mice had a significantly greater adhesion frequency for the priming antigen $\mathrm{NP}_{311-325}$ (left panel, Fig. 3b), than mice with no measurable antigen-specific Nur77 upregulation, allowing for the calculation of TCR:pMHCII affinity (middle panel, Fig. 3b). The affinity for influenza $\mathrm{NP}_{311-325}$ was below that for which we previously reported was necessary for detection by MHC class II tetramers $\left(>10^{-4} \mu \mathrm{m}^{4}\right.$; right panel, Fig. $3 b)^{9,39}$. When the affinity of $\mathrm{T}$ cells from five individual mice were assessed, mouse 2, 3, 4 and 5 displayed a range in affinity of $<10$-fold (Fig. 3b). TCR affinity ranges of 10 -fold or less are characteristic of clonal T-cell populations ${ }^{12,28,30,40}$, while polyclonal populations can possess a 1,000 -fold range in affinity 9,41 . Of note, mouse number 1 displayed a wider range of TCR affinity that appeared as distinct higher-affinity and lower-affinity populations, suggesting the presence of two clones. This is consistent with the frequency of $\mathrm{T}$ cells $\left(1.2 \times 10^{6} \mathrm{CD} 4+\mathrm{T}\right.$ cells transferred $)$ for that animal being above the limiting dilution level and the potential presence of more than one clone. A polyclonal assessment of TCR affinity for $\mathrm{NP}_{311-325}$ was included (Fig. 3b), displaying the wider affinity range ( $>100$-fold) observed in polyclonal responses and demonstrating a similar range to the single clones measured (Fig. 3b). Overall, the micropipette analysis defined the presence of antigen-specific $\mathrm{T}$ cells with affinities below the minimum required for tetramer staining, while suggesting their clonality and confirming the antigen specificity of the functional Nur77gfp LDA measurements.

To further demonstrate clonality of the LDA experiments, single-cell TCR $\beta$ sequencing was performed on Nur77gfp -positive and -negative populations from $\mathrm{NP}_{311-325}$ LDA mice. All LDA-positive mice were highly enriched for a single-TCR $\beta$ clonotype $(>70 \%)$ with no TCR sequences shared between the mice (shared sequences identified as same colour in individual mice, Fig. 3c). The remaining sequences from each mouse 

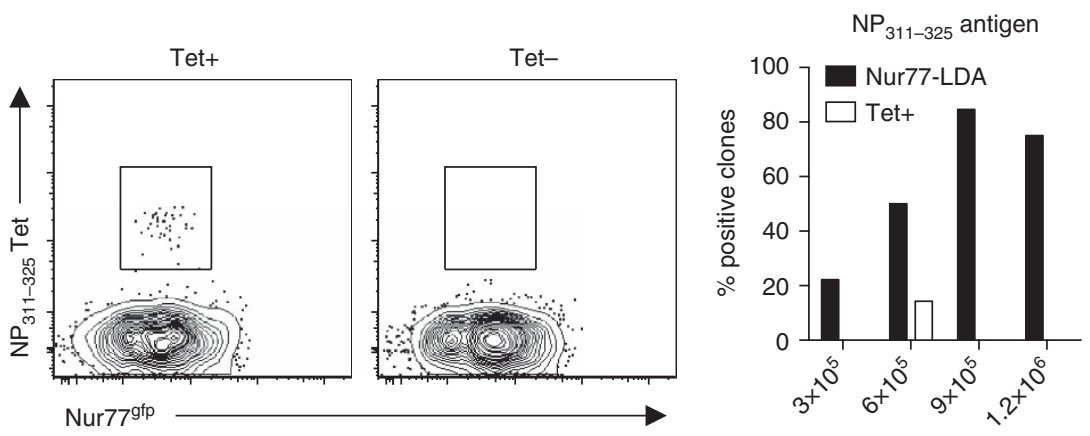

CD4 T cells transferred
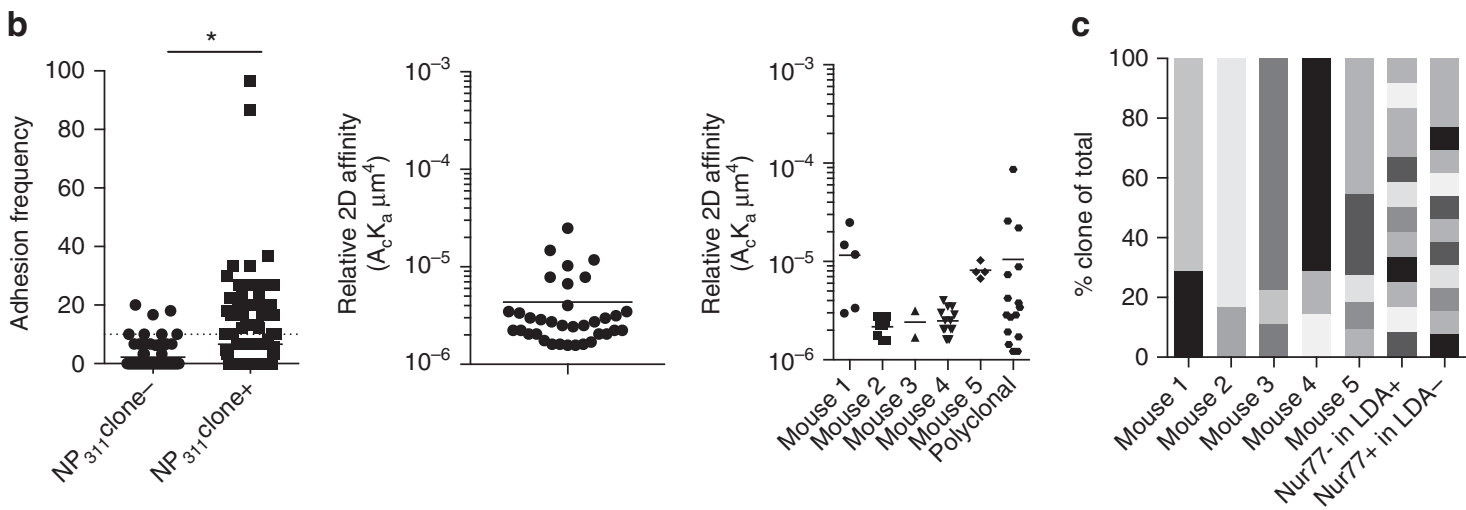

Figure 3 | In vivo LDA identifies low-affinity CD4 + T-cell clones. (a) Representative NP $311-325$ Tet staining in TCR $\alpha^{-/-}$LDA mice with both a Tet + positive (left) and negative (right), with only 1 out of 34 mice possessing a Tet + -positive clone. (b) MP on single CD4 + T cells isolated from positive and negative LDA mice as identified by CD69/Nur77 (data combined from two independent experiments, $n=2-3$ mice, Student's $t$-test, ${ }^{\star} P=0.0073$ ). MP affinities on individual positive LDA clones following $\mathrm{NP}_{311-325} / \mathrm{CFA}$ immunization along with a separate analysis of the polyclonal repertoire (single points represent individual cells). (c) Single-cell TCR $\beta$ sequencing from LDA-positive and -control mice. Individual colours represent unique TCR $\beta$ CDR3

sequences, with each column representing a single mouse.

correlated with the background green fluorescent protein expression identified in all Nur77gfp animals. No TCR $\beta$ chain predominated in mice lacking antigen-specific $\mathrm{T}$ cells clones as defined by LDA or amongst the Nur77gfp - T cells in a mouse with a positive clone identified by LDA (Fig. 3c). These data demonstrate the in vivo LDA with TCR repertoire analysis can identify and isolate single, lower-affinity $\mathrm{T}$-cell clones and provides an effective method for calculating the precursor number of Tet $-\mathrm{CD} 4+\mathrm{T}$ cells in the naive repertoire.

T-cell expansion is correlative with naive $\mathrm{T}$-cell numbers. As we estimated the total antigen-specific CD4 $+\mathrm{T}$ cell for six epitopes in the naive mouse and found them to outnumber Tet + counterparts, we wanted to next determine the contribution of the low-affinity CD $4+\mathrm{T}$ cells on immune expansion. Naive Tet + precursor frequency predicts the immunodominance of an antigen-specific T-cell population ${ }^{4,8}$, but these assays have not included Tet $-\mathrm{CD} 4+\mathrm{T}$ cells or even those antigens enriched for lower-affinity TCRs such as self antigens like MOG. Analysis of foreign antigen-specific Tet + CD $4+\mathrm{T}$ cells after immunization with peptide in CFA confirmed the positive correlation between $\left(r^{2}=0.41, \quad P<0.0001\right)$ precursor and expanded T-cell numbers (different antigens represented by each point, dotted line, Fig. 4a, gating strategy Supplementary Fig. 2). Yet, when MOG self-antigen-specific CD $4+\mathrm{T}$ cells are included in the tetramer analysis (solid line, Fig. 4a) the $r^{2}$ value decreases to 0.22 with a $P$ value of 0.0021 , indicating factors other than precursor frequency may contribute to Tet $+\mathrm{T}$-cell expansion to self-antigens ${ }^{42,43}$. Next, MP analysis of $\mathrm{T}$ cells from mice immunized 14 days earlier with peptide/CFA showed a strong correlation with the naive precursor frequency measured by LDA (Fig. $4 \mathrm{~b}$ ). When lower-affinity $\mathrm{T}$ cells measured by MP were included in the expanded T-cell numbers, the naive to expanded T-cell correlation improves, even with the inclusion of CD4 + T cells specific for MOG self-antigen (Fig. 4b). Further comparison of the precursor numbers from tetramer staining and LDA calculations revealed a significant correlation between the methods, suggesting tetramer can be used to roughly estimate the hierarchy within naive populations, though it still vastly underestimates naive T-cell numbers (Fig. 4c). In addition, MP identifies $\sim 10-150$-fold greater numbers of expanded antigenspecific CD $4+\mathrm{T}$ cells than by tetramer, significantly altering our understanding of the extent of CD4 + T-cell expansion.

To determine how TCR:pMHCII affinity influences the expansion of $\mathrm{T}$ cells during the primary immune response, the ratio of Tet + to Tet $-\mathrm{T}$ cells were compared for all epitopes in both naive and immunized samples (Fig. 5a). No increase in the frequency of Tet $+\mathrm{T}$ cells was found at the peak of expansion (day 14 after immunization), signifying Tet $+\mathrm{T}$ cells did not gain a competitive advantage over lower-affinity $\mathrm{T}$ cells. In fact, a significant reduction in the frequency of Tet $+\mathrm{CD} 4+\mathrm{T}$ cells of the total expanding population was found for all antigens (Fig. 5a). This was not a function of the time point measured, as kinetic analysis of the MOG-specific repertoire revealed higher-affinity $\mathrm{T}$ cells contributed the most in naive state, with significantly less involvement as the immune response progressed (Fig. 5b). The large contribution of lower-affinity CD4 + T cells 

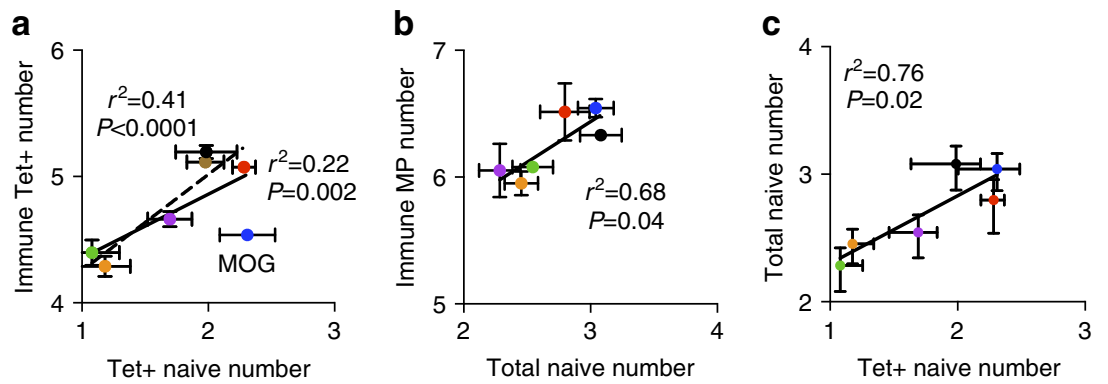

Figure 4 | Total precursor numbers predict expansion of CD4 + T cells. Each point is a unique antigen-specific population: $\mathrm{MOG}_{38-49}\left(\right.$ blue), $\mathrm{GP}_{66-77}$

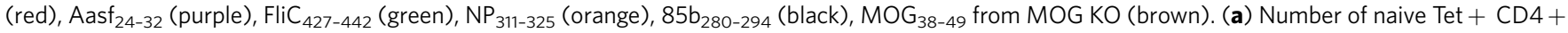
T cells (log transformed) compared with Tet + CD4 + T cells 14 days after immunization (log transformed; $n=5-6$ mice per group, data represented as mean \pm s.e.m.). (b) Number of antigen-specific CD4 + T cells (log transformed) identified by MP after immunization correlated with previously calculated precursor numbers (log transformed; expanded data: 12 experiments, two to three mice per point, data represented as mean \pm s.e.m.). (c) Correlation of the number of naive T cells (both log transformed) as identified by tetramer and LDA (data represented as mean \pm s.e.m.).
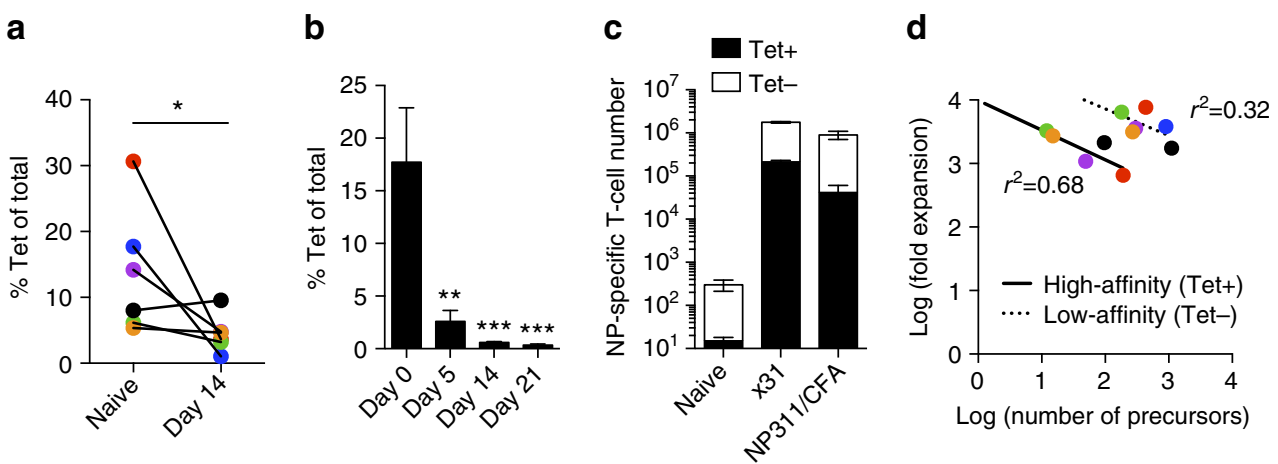

Figure 5 | Low-affinity CD4 + T cells predominate CD4 + T-cell immune responses. Each point is a unique antigen-specific population: MOG $_{38-49}$ (blue), GP 66-77 (red), Aasf $24-32$ (purple), FliC $427-442$ (green), NP $311-325$ (orange), 85b $280-294$ (black) and MOG $38-49$ from MOG KO (brown). (a) Frequency of Tet + CD4 + T cells in the naive and day 14 immunized repertoires (data shown as mean frequency for each antigen, paired Student's $t$-test, ${ }^{\star} P<0.05$ ). (b) Frequency of MOG-Tet + cells in the total MP + T cells during the immune response to $\mathrm{MOG}_{35-55} / \mathrm{CFA}$ immunization (data shown as mean \pm s.e.m., one-way analysis of variance, ${ }^{\star \star} P<0.01,{ }^{\star \star \star} P<0.001$ with day 0 as a reference value). (c) Enumeration of Tet + and Tet - NP311-specific CD4 + T-cell contribution from either naive, day 10 post $\times 31$ influenza infection, or NP311/CFA immunizations (naive data taken from Fig. 4a, expanded data contain four independent experiments, with two mice each, data represented as mean \pm s.e.m.). (d) Plot of precursor number (log transformed) versus fold expansion (log transformed) of high-affinity and low-affinity T cells as identified by tetramer, LDA and MP.

was also found in the $\mathrm{NP}_{311-325}$-specific $\mathrm{T}$-cell population responding during influenza $\mathrm{x} 31$ infection and NP311/CFA immunization (Fig. 5c). This demonstrates that low-affinity T-cell recruitment does not only occur in response to CFA, but is equally present during infection. Next, the fold expansion of antigenspecific populations (Tet + and Tet - , each point is a unique antigen) was graphed separately as a function of precursor frequency (Fig. 5d), finding CD4 + T-cell populations with smaller precursor numbers exhibiting greater expansion. MOG was removed from the analysis for higher-affinity $\mathrm{T}$ cells due to its altered expansion due to tolerance. When the higher-affinity (solid line) and lower-affinity (dotted line) populations were compared at the same precursor frequency, the lower-affinity $\mathrm{T}$ cells have the potential to expand to a greater number than the higher-affinity, Tet $+\mathrm{T}$ cells (Fig. 5d). Interestingly, the slopes of the two lines generated are similar (Tet $+:-0.47$, Tet $-:-0.42$ ), signifying the two populations of cells compete within themselves comparably (Fig. 5d). Therefore, TCR:pMHCII affinity does not control the accumulation of $\mathrm{CD} 4+\mathrm{T}$ cells during the immune response, and instead immune activation selects for a diverse range of affinities during primary immune expansion.

\section{Discussion}

Precise quantification of T-cell precursor numbers and expansion is essential for understanding the function of the adaptive immune system, vaccine design and adoptive $\mathrm{T}$-cell therapeutics. Initially, T-cell numbers were defined by in vitro LDA based on the frequency of functionally responsive cells ${ }^{38}$. TCR-Tg mice allowed for the study of the naive frequency and expansion of monoclonal populations, but did not address the diversity present in a polyclonal immune response ${ }^{44,45}$. The advent of pMHC tetramer technology began to address the limitation of monoclonal analysis by providing improved assessment of precursor and expanded T-cell numbers in more clonally diverse populations ${ }^{4,7}$. Key insight into the relationship between precursor numbers, expansion and cross-reactivity was provided with the use of the tetramers although tetramer-based affinity and avidity interactions do not fully encompass polyclonal T-cell responses, especially those enriched for lower-affinity interactions, that is ones specific for self-antigen ${ }^{8,42}$. Previous studies had identified these low-affinity, Tet - T cells, but have never developed a way to quantify, identify and phenotype these polyclonal $\mathrm{T}$ cells in their naive or activated state ${ }^{11,25}$. Therefore, this work adds to these initial observations, allowing for the study 
of low-affinity, Tet - $\mathrm{T}$ cells in a polyclonal model, providing increased depth of understanding to CD4 + T-cell responses.

A major goal of this work was to quantify the precursor number of antigen-specific CD4 $+\mathrm{T}$ cells inclusive of loweraffinity $\mathrm{T}$ cells missed by MHC class II tetramers. In calculating the total naive $\mathrm{T}$-cell numbers, we chose to perform these experiments in T-cell-deficient mice. As the LDA is a digital response (cells are either present or absent), the lymphopenic environment increases the signal to noise ratio of the assay by allowing for larger proliferation of the single clone being measured for Nur77 expression after restimulation. The lymphopenic environment has minimal impact on the competition dynamics between high-affinity and low-affinity T cells, as LDA calculations were similar between mice with (WT) and without $(\mathrm{TCR} \alpha-/-)$ T cells. Therefore, we can conclude the lymphopenic environment has minimal impact on competition dynamics between high-affinity and low-affinity $\mathrm{T}$ cells in the LDA calculations. This is in agreement with previous work as groups have suggested the initial precursor frequency of $\mathrm{CD} 4+\mathrm{T}$ cells is low enough to prevent the competition between antigen-specific $\mathrm{T}$ cells ${ }^{24}$. Once $\mathrm{T}$ cells have expanded, some infer that competition for resources could favour the dominance of individual clonotypes that many would presume relate to TCR affinity ${ }^{19,20}$. Instead for all polyclonal responses analysed here, we find a distribution of TCRs where low-affinity CD4 $+\mathrm{T}$ cells expand from their naive numbers to remain more numerous in the immune repertoire. On secondary challenge, both highaffinity and low-affinity $\mathrm{T}$ cells have been shown to have an advantage in survival ${ }^{19,22}$. We hypothesize that there will be narrowing of the antigen-specific TCR $\beta$ population, as only some of the clones will respond to antigen, but between the highaffinity and low-affinity populations there will be no enhanced survival. This is likely due to mechanisms that can modulate TCR signalling such as TCR $\beta$ downregulation ${ }^{22}$ and Lck-coreceptor conjugation $^{46}$, which have been shown to occur after primary immune responses.

Our data indicate TCR affinity does not predict the peak expansion of $\mathrm{T}$ cells in response to primary antigen exposure, though we do not know if affinity affects the efficiency of entry into the immune response. The correlation between affinity and expansion has been proposed before, but conflicting data exists. For example one could conclude that affinity does not correlate with expansion to antigen based on Tg-barcoding experiments ${ }^{47,48}$. In these experiments, a single OT-I T cell can have a range of contribution to the expanded repertoire even though each T-cell expressed the same clonal TCR ${ }^{47,48}$. As well, highaffinity and low-affinity CD4 $+\mathrm{T}$ cells show similar efficiency of proliferation in both in vitro and in vivo work ${ }^{22,28}$. On the other hand, the use of altered peptide ligands (APLs) or a fixed $\operatorname{TCR} \beta$ chain $\mathrm{Tg}$ has demonstrated the magnitude of expansion and contribution to the total repertoire was correlative with TCR:pMHC affinity ${ }^{21,23}$. It is unclear what factors are different between these experiments, but potentially infection type, TCR$\mathrm{Tg}$ T-cell thymocyte development or competition with the endogenous repertoires may affect competition and expansion. Thymocyte development has been shown to play an important role in setting the basal activity of $\mathrm{T}$ cells ${ }^{49}$, but TCR-Tg $\mathrm{T}$ cells would not undergo these varied developmental consequences, thereby potentially altering an important negative regulatory loop in T-cell development with different affinities. Our data based on the polyclonal T-cell response to six different antigens indicates that TCR affinity does not influence clonal expansion dominance.

The identification of low-affinity CD4 $+\mathrm{T}$ cells always comes with questions about the functionality of this T-cell subpopulation, as it is hypothesized that low-affinity equates to sub-optimal and that the enumeration of Tet + and functional responses leads to similar magnitudes ${ }^{6,50}$. However, these assumptions are not completely accurate. Transcription factor profiling of the CFA immune response has shown Tet + cells have at most $20 \% \mathrm{~T}$-bet $+\left(\mathrm{T}_{\mathrm{H}} 1\right.$ lineage-defining transcription factor $)$ expression $^{8,43}$. In contrast, experiments monitoring cytokine secretion by $\mathrm{T}$ cells in this same immune response have show interferon- $\gamma$ (IFN- $\gamma$ ) enzyme-linked immunoSpot (ELISPOT) data and Tet + T-cell number equate ${ }^{8,42}$. Therefore, Tet $+\mathrm{T}$-bet $+\mathrm{CD} 4+\mathrm{T}$ cells cannot be the sole source of IFN- $\gamma$ production in ELISPOT experiments. Likely, lower-affinity $\mathrm{T}$ cells are contributing to this pool of antigen-specific $\mathrm{T}$ cells identified by ELISPOT. Recent work using a pMHCII dodecamer $(12$ pMHCII arms instead of four) supports this hypothesis as they found Tet - , but dodecamer $+\mathrm{T}$ cells exhibited similar function to Tet $+\mathrm{T}$ cells ${ }^{51}$. The dodecamer reagent, while giving increased numbers as compared with tetramers, only showed two to three times greater identification of T cells, which is still an underestimation as compared with the seven to eight times increase we find using Nur77 in the naive repertoire and $>10 \times$ increases found using the micropipette. Please note, that Nur77, like all functional responses, underestimates the numbers of CD $4+\mathrm{T}$ cells in an immune response as not every $\mathrm{T}$ cell can respond at a given time. For example, analysis of cloned TCRs in a retrogenic system found that several retrogenic-TCRs (TCR-Rg) could cause autoimmune diabetes ${ }^{30}$, but within each TCR-Rg group, only a fraction could upregulate Nur77 even though the population shared the same TCR. Therefore, induction of Nur77 expression as readout by the reporter is likely less sensitive then the measurement of effector functionality and likely independent of TCR affinity. More work will be needed to understand the interaction of TCR affinity, T-cell signalling thresholds and their correlation with effector function.

Since polyclonal TCR affinities during the CD4 + T-cell response are maintained from the naive state, this diversity most likely serves a functional purpose, as biological systems are seldom wasteful. In T-cell immunotherapeutics, some TCRs have been engineered for higher-affinity pMHC interactions with the belief that the highest-affinity TCR would generate the most efficacious immunodominant respons $\mathrm{e}^{52}$. Of interest, the selection of engineered higher-affinity TCRs has been both successful and disastrous in patients with outcomes that have included death ${ }^{53,54}$. This points to a need for further understanding of what is an optimal affinity range for effective immunity, with recent data showing greater function of TCRs with intermediate affinity ${ }^{22}$. Instead of a single unusually highaffinity TCR, a range of affinities might prove more advantageous. Our data demonstrates that population diversity is a property of the immune response and that mechanisms maintain a diverse affinity range of $\mathrm{CD} 4+\mathrm{T}$ cells in a polyclonal population. For example, population diversity of antigen responsive $\mathrm{T}$ cells can be seen in the production and use of interleukin-2. While only a subset of $\mathrm{T}$ cells produce interleukin-2, both high-affinity and low-affinity $\mathrm{T}$ cells may use this key growth cytokine ${ }^{36,55,56}$. A counterpoint to the concept of favoring higher-affinity $\mathrm{T}$ cells are the findings that lower-affinity $\mathrm{T}$ cells possess preferred differentiation patterns, with these $\mathrm{T}$ cells more likely to acquire $\mathrm{T}_{\mathrm{H}} 2, \mathrm{~T}_{\mathrm{FH}}$ or $\mathrm{T}_{\mathrm{CM}}$ phenotypes $6,36,50,57,58$. As well, data has shown that initial induction of peripherally derived regulatory $\mathrm{T}$ cells can arise from lower-affinity TCR:pMHCII interactions ${ }^{59,60}$. By understanding the population characteristics of lower-and higher-affinity CD4+ $\mathrm{T}$ cells together, unique immune treatments may be developed with targeted characteristics.

Inclusion of lower-affinity TCRs in immune repertoires leads to a large increase in the numbers of $\mathrm{CD} 4+\mathrm{T}$ cells specific for a single epitope, altering our understanding of TCR cross-reactivity. TCR cross-reactivity, defined as a single $\alpha \beta$ 
TCR binding to multiple pMHC, has been shown to be necessary for complete immune protection against pathogens, as there are a greater number of potential epitopes $\left(20^{9} \sim 5.12 \times 10^{11}\right)$ than estimated mouse $\alpha \beta$ TCR clonotypes $\left(2 \times 10^{6}\right)^{2,61}$. Our findings of increased $\mathrm{CD} 4+\mathrm{T}$ cells specific for a single antigen increases the theoretical amount of TCR cross-reactivity required for complete immune protection by eightfold ${ }^{2}$. Due to the increase in cross-reactivity, the amount of $\mathrm{T}$ cells needed to protect an entire mouse, termed the protecton, may be similarly decreased due to the increased number of $\mathrm{T}$ cells for a single antigen ${ }^{3}$. Future work will need to clarify how affinity impacts cross-reactivity or if there is any correlation at all.

In conclusion, we find the expansion of naive CD4 $+\mathrm{T}$ cells in the primary immune response is independent of TCR:pMHCII affinity, while also quantitating the total number of $\mathrm{CD} 4+\mathrm{T}$ cells in an immune response. Quantitation of the total repertoire reveals that up to $90 \%$ of the CD4 $+\mathrm{T}$ cells participating in the immune response are ignored by conventional analyses. It will be of interest to determine if this frequency of ignored CD4 T cells is a constant or if it can be altered based on the antigen delivery. Potentially, priming antigen doses used here could affect the ratio of high-affinity to low-affinity $\mathrm{T}$ cells, as it has been shown antigen dose changes the expansion and differentiation of highaffinity, Tet $+\mathrm{CD} 4+\mathrm{T}$ cells ${ }^{26}$. However, recent work has shown use of low-antigen concentration to activate CD4 + TCR-Tg T cells with different affinities for the same antigen causes similar primary division rates, thereby maintaining the diversity of the $\mathrm{T}$-cell population even across a range of affinities ${ }^{22}$. Since loweraffinity $\mathrm{CD} 4+\mathrm{T}$ cells have been shown to have similar roles as higher-affinity $\mathrm{T}$ cells ${ }^{26,36}$, the sole use of pMHCII tetramers underestimate the diversity and richness of the immune system by not monitoring these lower-affinity cells. The expansion and continual presence of these $\mathrm{T}$ cells likely highlight the need of affinity diversity for maintenance of a healthy immune system and limiting microbial immune evasion ${ }^{62-64}$. Future studies are needed to fully understand how low-affinity $\mathrm{T}$ cells may impact human immune health, as we predict to see similar total numbers of antigen-specific $\mathrm{T}$ cells in mice and humans given that they possess similar repertoire diversity and specificity ${ }^{2,65}$.

\section{Methods}

Mice. C57BL/6NCr (WT) mice were purchased from the National Cancer Institute, while MOG KO mice ${ }^{66}$ were a gift from Hugh Reid and were bred on site. Thy $1.1+$, Nur77gfp and TCR $\alpha-/-$ mice were purchased from Jackson Laboratories and were bred on site. Mice were 6-8 weeks old when used for experiments. Both males and females were used. WT mice immunized with $\mathrm{MOG}_{35-55}$ were monitored for weight loss due to experimental autoimmune encephalomyelitis (EAE) and were killed if weights fell $<20 \%$ of initial starting weight. Experimental sample sizes were chosen from previous experiments on naive and expanded T-cell numbers ${ }^{8}$. No mice were excluded from analysis. No randomization was performed for experiments and no investigator blinding was performed. All animals were housed in an Emory University Department of Animal Resources facility (Atlanta, GA, USA). Permission was granted and performed in accordance with the protocols of the Institutional Animal Care and Use Committee.

Peptide priming. MOG $_{35-55}$ (MEVGWYRSPFSRVVHLYRNGK), 85b $\mathrm{b}_{280-294}$ (FQDAYNAAGGHNAVF) GP $61-81$ (GLKGPDIYKGVYQFKSVEFD), Aasf $_{24-32}$ (VSSPAVQES), $\mathrm{NP}_{311-325}$ (QVYSLIRPNENPAHK) and $\mathrm{FliC}_{427-441}$ (VQNRFNSAITNLGNT) peptides were synthesized on a Prelude peptide synthesizer (Protein Technologies, Inc., Tuscon, AZ, USA). For all peptide immunizations, $200 \mu \mathrm{g}$ of the peptide was emulsified in $375 \mu \mathrm{g}$ of CFA and injected subcutaneously into the flank of a mouse on days 0 and 7 ( $150 \mu \mathrm{l}$ total volume per injection). CFA was made in-house by mixing $20 \mathrm{ml}$ of Incomplete Freund's Adjuvant (Becton Dickinson, Franklin Lakes, NJ, USA) and $100 \mathrm{mg}$ of desiccated Mycobacterium tuberculosis H37 Ra (Becton Dickinson). On days 0 and 2, $300 \mathrm{ng}$ of pertussis toxin (Ptx, List Biological Labratories, Campbell CA, USA) was injected intraperionteallly in all immunizations to compare both the self and foreign immune responses.
Tetramer enrichments. Tetramers and monomers were provided by the National Institute of Allergy and Infectious Diseases Tetramer Core Facility at Emory University or were a generous gift of Marc Jenkins. Tetramer enrichment and staining was performed as previously described ${ }^{67}$. Briefly, mouse peripheral lymphoid organs (spleen and inguinal, para-aortic, brachial, axillary, cervical and mesenteric lymph nodes) were processed into a single-cell suspension. Cells were then stained with the respective tetramer (phycoerythrin (PE)- and/or allophycocyanin (APC)-conjugated, $4 \mu \mathrm{g} \mathrm{ml}^{-1}$ final concentration) for $60 \mathrm{~min}$ at room temperature, washed, stained with $50 \mu \mathrm{l}$ of anti-PE or anti-APC magnetic microbeads for $30 \mathrm{~min}$ on ice (Miltenyi Biotec, Germany), washed and enriched on a magnetized LS column (Miltenyi Biotec). The bound and flow-through samples were then sampled to determine population counts using AccuCheck microbeads (Invitrogen, Carlsbad, CA, USA) and stained for analysis by flow cytometry. Antibodies used are show in Supplementary Table 1. For intracellular staining, cells were treated with the Tonbo or eBioscience Fixation and Permiabilization kits as per the manufacturer protocol. Samples were collected on an LSR II (Becton Dickinson) and analysed using FlowJo (Treestar, Ashland, OR, USA).

CD4 + T-cell adoptive transfer. Splenocytes from naive mice were collected and processed into a single-cell suspension. CD $4+\mathrm{T}$ cells were purified following manufacturer instructions using the CD4 + T-cell negative isolation kit (Miltneyi Biotec). Purified CD $4+\mathrm{T}$ cells were analysed by flow cytometry for purity and counted by flow cytometry using AccuCheck microbeads (Invitrogen). Purified $\mathrm{CD} 4 \mathrm{~s}$ were injected intravenously into recipient mice and immunized $24 \mathrm{~h}$ later. Park rate at $24 \mathrm{~h}$ was measured in TCR $\alpha^{-l-}$ and found to be $\sim 20 \%$ (Supplementary Fig. 3).

Nur77 analysis. For experiments comparing donor high-affinity and low-affinity $\mathrm{T}$ cells in a WT mouse using tetramers, spleens and lymph nodes from recipient, immunized mice were collected and processed into single-cell suspensions.

Tetramer enrichment was performed as described above. Bound samples were then analysed by flow cytometry. For adoptive transfer limiting dilution experiments in WT mice, Thy1.2 enrichment was performed using anti-Thy1.2 antibody and anti-APC magnetic Microbeads (Miltenyi Biotec) following manufacturer protocol For Nur77 analysis in WT mice flow-through (FT) samples were used and not enriched. For all cases, prepared samples were stimulated for $18-22 \mathrm{~h}$ in quadruplicate with $10 \mu \mathrm{g} \mathrm{ml}^{-1}$ of peptide (one specific peptide and three non-specific peptides). Samples were then collected and stained for analysis of donor

(Thy1.2 + ) CD4 + T-cell Nur77 upregulation by flow cytometry. For analysis of the frequency of Nur77 upregulation, non-specific background was averaged and subtracted from both specific and non-specific samples, and then graphed. Discrimination of positive and negative clones for LDA was performed as described in the section on calculations with the values being reported as mean $\pm 95 \%$ confidence intervals.

For experiments calculating naive precursor frequency of low-affinity CD4+ $\mathrm{T}$ cells, spleens from recipient TCR $\alpha^{-/-}$mice were collected and processed individually into single-cell suspensions. Splenocytes $\left(2-3 \times 10^{6}\right)$ from each mouse were plated in quadruplicate, with three samples stimulated with $100 \mu \mathrm{g} \mathrm{ml}^{-1}$ of peptide for $18-22 \mathrm{~h}$ and one sample remaining unstimulated. The unstimulated sample was used for pMHCII tetramer staining to detect higher-affinity CD4+ $\mathrm{T}$ cells. Stimulated splenocytes were collected, stained with antibodies shown and analysed by flow cytometry as described above. Discrimination of positive and negative clones was performed as described in the section on calculations.

Nur77 functional measurement. Spleen and lymph nodes of previously immunized mice were processed into a single-cell suspension and counted. Samples were split in half and both set of cells were stimulated with $10 \mu \mathrm{g} \mathrm{ml}^{-1}$ of peptide at a concentration of $1 \times 10^{7}$ cells per $\mathrm{ml}$ in complete media (RPMI $1640,10 \%(\mathrm{v} / \mathrm{v})$ FCS, $2 \mathrm{mM}$ L-glutatmine, $0.05 \mathrm{mM} 2$-mercaptoethanol and $0.05 \mathrm{mg} \mathrm{ml}^{-1}$ gentamicin sulfate) for $4 \mathrm{~h}$. One sample received $\mathrm{MOG}_{35-55}$ (antigen specific), while the other received $\mathrm{GP}_{61-81}$ (non-specific). Samples were then collected and tetramer enrichment was performed as described above. Both bound and flow-through samples were then analysed by flow cytometry.

TCRß sequencing. Single-cell Tcrb VDJ sequencing was performed as previously described $^{68}$. In preparation for sequencing, LDA experiments were performed for the $\mathrm{NP}_{311-325}$ antigen in TCR $\alpha^{-/-}$mice (see section on LDA). After restimulation and flow cytometry, the samples were analysed to determine if they possessed a low-affinity T-cell clone (see section on Calculations). Single CD4 + T cells from positive and negative LDA samples were then index-sorted by a FACS Aria II (Becton Dickinson) into a 96-well plate containing $2.5 \mu \mathrm{l}$ cDNA master mix (iScript cDNA Synthesis Kit, Bio-Rad). Column 12 of the 96-well plate did not receive cells, thereby acting as a negative control wells for each plate. After production of complementary DNA, nested Tcrb VDJ PCRs were performed on each sample and the negative control column was confirmed by gel electrophoresis. Samples were then sent to Beckman Coulter Genomics (Danvers, MA, USA) for Sanger sequencing. Individual sequences were tabulated and parsed by in-house designed software and then analysed by The International Immunogenetics Information system (IMGT) ${ }^{69-71}$. Non-productive sequences were not analysed. 
TCR affinity measurement. Spleens from immunized mice were removed on the noted days and processed into a single-cell suspension. CD4 $+\mathrm{T}$ cells were purified using the CD4 + T-cell positive selection kit (Miltenyi Biotec) as per manufacturer instructions. In parallel, $\mathrm{CD} 4+\mathrm{T}$ cells were counted by flow cytomtery using AccuCheck beads as described above. Red blood cells (RBCs) were isolated in accordance with the Institutional Review Board at Emory University and prepared as previously described ${ }^{12}$. RBCs coated with various concentrations of Biotin-X-NHS (EMD) were coated with $0.5 \mathrm{mg} \mathrm{ml}^{-1}$ streptavidin (Thermo Fisher Scientific, Waltham, MA, USA), followed by $1-2 \mu \mathrm{g}$ of pMHCII monomer. The pMHCII-coated RBCs were stained with anti-MHC class II PE antibody, and purified T cells were stained with anti-TCR $\beta$ (eBioscience, H57-597) PE antibody. The densities of I-A $\mathrm{A}^{\mathrm{b}}$ and TCR were calculated using BD QuantiBrite Beads (Becton Dickinson). The micropipette adhesion frequency assay was then preformed as previously described ${ }^{12}$. In brief, a pMHC-coated RBC and $\mathrm{T}$ cells were placed on opposing micropipettes and brought into contact by micromanipulation for a controlled contact area $\left(A_{c}\right)$ and time (t). The T cell was retracted at the end of the contact period, and the presence of adhesion (indicating TCR-pMHC binding) was observed by elongation of the RBC membrane. This TCR-RBC contact was repeated 25 times and the adhesion frequency $(\mathrm{Pa})$ was calculated. The relative $2 \mathrm{D}$ affinity $\left(\mathrm{A}_{\mathrm{c}} \mathrm{K}_{\mathrm{a}}\right)$ of each cell that had a Pa of $>10 \%$ was calculated using the $\mathrm{Pa}$ at equilibrium (where $\mathrm{t} \rightarrow \infty$ ) using the following equation: $\mathrm{A}_{\mathrm{c}} \mathrm{K}_{\mathrm{a}}=-\ln [1-\mathrm{Pa}(\infty)] /(\mathrm{mrml})$, where $\mathrm{mr}$ and $\mathrm{ml}$ reflect the receptor (TCR) and ligand (pMHC) densities, respectively. The total frequency of cells that bound to pMHCII-coated RBCs was tabulated and used for the calculation of antigen specific CD4 + T-cell numbers below. Previous reports have shown that as few as 10 cells in a polyclonal population need to be ran to generate an average affinity for the population, while considerably fewer cells (estimated to be five to seven cells) in a monoclonal repertoire need to be measured for an average affinity ${ }^{6}$. For each antigen, the number of binders and cells ran is as follows (shown as binders/cells ran): WT MOG $35-55$ (33/95), KO MOG $35-55$ (27/80), GP G1-81 (38/174), FliC $427-441$ (11/154), Aasf $24-32$ (11/165), $\mathrm{NP}_{311-325}$ (17/249) and 85b

Influenza $\mathbf{x} 31$ infections. WT mice were infected intranasally with influenza $\mathrm{A} / \mathrm{HKx} 31(\mathrm{H} 3 \mathrm{~N} 2)$ at $30,000 \mathrm{EID}_{50}(50 \%$ egg infectious doses) as previously described $^{72}$. Spleens were collected at day 10 post infection. Magnetic enrichment was performed using $\mathrm{CD} 4+$-positive selection following manufacturer protocol (Miltenyi Biotec). Purified cells were then stained with $4 \mu \mathrm{g} \mathrm{ml}^{-1}$ NP311:I-A ${ }^{\mathrm{b}}$ PE tetramer for $60 \mathrm{~min}$ at room temperature or used in the MP assay to determine the number of antigen-specific cells.

Calculations. For Nur77gfp LDA experiments, all samples were stimulated with their immunized antigen $\left(100 \mu \mathrm{g} \mathrm{ml}^{-1}\right)$ and two to three other non-specific antigens $\left(100 \mu \mathrm{g} \mathrm{ml}^{-1}\right)$. The frequencies of $\mathrm{CD} 44^{+} \mathrm{Nur} 77^{\text {ffp }}+\mathrm{CD} 69^{+} \mathrm{CD} 4+$ $\mathrm{T}$ cells were tabulated from specific and non-specific antigen controls. Samples were determined to be positive if the frequency of Nur77gfp $+\mathrm{CD} 69^{+} \mathrm{CD} 4+$ $\mathrm{T}$ cells in the antigen-specific sample was three s.d.'s above the mean of the averaged non-specific controls. The number of antigen-specific T cells from the LDA curves was calculated using an online calculator from a previously described method and reported as mean \pm the $95 \%$ confidence interval $^{73}$.

To calculate the number of $\mathrm{CD} 4+\mathrm{T}$ cells specific for a given antigen by MP, the frequency of non-specific binders was determined by performing the MP assay on CD4 + T cells from mice immunized with non-specific peptide in CFA (Supplementary Fig. 4). These background-binding frequencies were subtracted from the frequencies generated in antigen-specific experiments and total numbers of antigen-specific $\mathrm{CD} 4+\mathrm{T}$ cells were calculated from previously generated absolute counts of $\mathrm{CD} 4+\mathrm{T}$ cells in the spleen.

Statistical analysis. One-way analysis of variance, two-tailed, unpaired Student's $t$-tests, linear regression and two-tailed Student's $t$-tests were performed using Prism (GraphPad, LaJolla, CA, USA) Software.

Data availability. The data and analysis software that support the findings of this study are available from the corresponding author on request.

\section{References}

1. Nikolich-Zugich, J., Slifka, M. K. \& Messaoudi, I. The many important facets of T-cell repertoire diversity. Nat. Rev. Immunol. 4, 123-132 (2004).

2. Zarnitsyna, V. I., Evavold, B. D., Schoettle, L. N., Blattman, J. N. \& Antia, R. Estimating the diversity, completeness, and cross-reactivity of the $t$ cell repertoire. Front. Immunol. 4, 485 (2013).

3. Cohn, M. \& Langman, R. E. The protecton: the unit of humoral immunity selected by evolution. Immunol. Rev. 115, 5-261 (1990).

4. Moon, J. J. et al. Naive CD4 $(+)$ T cell frequency varies for different epitopes and predicts repertoire diversity and response magnitude. Immunity 27, 203-213 (2007)

5. Jenkins, M. K. \& Moon, J. J. The role of naive T cell precursor frequency and recruitment in dictating immune response magnitude. J. Immunol. 188, 4135-4140 (2012).
6. Martinez, R. J. \& Evavold, B. D. Lower affinity T cells are critical components and active participants of the immune response. Front. Immunol. 6, 1-10 (2015).

7. Altman, J. D. et al. Phenotypic analysis of antigen-specific T lymphocytes. Science 274, 94-96 (1996).

8. Nelson, R. W. et al. T cell receptor cross-reactivity between similar foreign and self peptides influences naive cell population size and autoimmunity. Immunity 42, 95-107 (2014).

9. Sabatino, J. J., Huang, J., Zhu, C. \& Evavold, B. D. High prevalence of low affinity peptide-MHC II tetramer-negative effectors during polyclonal CD4+ T cell responses. J. Exp. Med. 208, 81-90 (2011).

10. Kersh, A. E., Edwards, L. J. \& Evavold, B. D. Progression of relapsing-remitting demyelinating disease does not require increased TCR affinity or epitope spread. J. Immunol. 193, 4429-4438 (2014).

11. Crawford, F., Kozono, H., White, J., Marrack, P. \& Kappler, J. Detection of antigen-specific $\mathrm{T}$ cells with multivalent soluble class II MHC covalent peptide complexes. Immunity 8, 675-682 (1998).

12. Huang, J. et al. The kinetics of two-dimensional TCR and PMHC interactions determine T-cell responsiveness. Nature 464, 932-936 (2010).

13. Wooldridge, L. et al. Tricks with tetramers: how to get the most from multimeric peptide-MHC. Immunology 126, 147-164 (2009).

14. Wooldridge, L. et al. Interaction between the CD8 coreceptor and major histocompatibility complex class I stabilizes $\mathrm{T}$ cell receptor-antigen complexes at the cell surface. J. Biol. Chem. 280, 27491-27501 (2005).

15. Holler, P. D. \& Kranz, D. M. Quantitative analysis of the contribution of TCR/ pepMHC affinity and CD8 to T cell activation. Immunity 18, 255-264 (2003).

16. Boniface, J. J. et al. Initiation of signal transduction through the T cell receptor requires the peptide multivalent engagement of MHC ligands. Immunity $\mathbf{9}$, 459-466 (1998).

17. Xiong, Y., Kern, P., Chang, H.-C. \& Reinherz, E. L. T cell receptor binding to a pMHCII ligand is kinetically distinct from and independent of CD4. J. Biol. Chem. 276, 5659-5667 (2000).

18. Huppa, J. B. et al. TCR-peptide-MHC interactions in situ show accelerated kinetics and increased affinity. Nature 463, 963-967 (2010).

19. Busch, D. H. \& Pamer, E. G. T cell affinity maturation by selective expansion during infection. J. Exp. Med. 189, 701-710 (1999).

20. Savage, P. A., Boniface, J. J. \& Davis, M. M. A kinetic basis for T cell receptor repertoire selection during an immune response. Immunity 10, 485-492 (1999).

21. Malherbe, L., Hausl, C., Teyton, L. \& McHeyzer-Williams, M. G. Clonal selection of helper $\mathrm{T}$ cells is determined by an affinity threshold with no further skewing of TCR binding properties. Immunity 21, 669-679 (2004).

22. Gallegos, A. M. et al. Control of T cell antigen reactivity via programmed TCR downregulation. Nat. Immunol. 17, 379-386 (2016).

23. Zehn, D., Lee, S. Y. \& Bevan, M. J. Complete but curtailed T-cell response to very low-affinity antigen. Nature 458, 211-214 (2009).

24. Kedl, R. M. et al. T cells compete for access to antigen-bearing antigenpresenting cells. J. Exp. Med. 192, 1105-1113 (2000).

25. Rees, W. et al. An inverse relationship between $\mathrm{T}$ cell receptor affinity and antigen dose during $\mathrm{CD} 4(+) \mathrm{T}$ cell responses in vivo and in vitro. Proc. Natl Acad. Sci. USA 96, 9781-9786 (1999).

26. Tubo, N. J. et al. Single naive CD4(+) T cells from a diverse repertoire produce different effector cell types during Infection. Cell 153, 785-796 (2013).

27. Tubo, N. J. et al. Most microbe-specific naïve $\mathrm{CD} 4+\mathrm{T}$ cells produce memory cells during infection. Science 351, 511-514 (2016).

28. Rosenthal, K. M. et al. Low 2-dimensional CD4 T cell receptor affinity for myelin sets in motion delayed response kinetics. PLoS ONE 7, e32562 (2012).

29. Moran, A. E. et al. T cell receptor signal strength in Treg and iNKT cell development demonstrated by a novel fluorescent reporter mouse. J. Exp. Med. 208, 1279-1289 (2011)

30. Bettini, M. et al. TCR affinity and tolerance mechanisms converge to shape T cell diabetogenic potential. J. Immunol. 193, 571-579 (2014).

31. Stritesky, G. L. et al. Murine thymic selection quantified using a unique method to capture deleted T cells. Proc. Natl Acad. Sci. USA 110, 4679-4684 (2013).

32. Au-Yeung, B. B. et al. A sharp T-cell antigen receptor signaling threshold for T-cell proliferation. Proc. Natl Acad. Sci. 111, E3679-E3688 (2014).

33. Stadinski, B. D. et al. Hydrophobic CDR3 residues promote the development of self-reactive T cells. Nat. Immunol. 17, 946-955 (2016).

34. Feng, Y. et al. A mechanism for expansion of regulatory T-cell repertoire and its role in self-tolerance. Nature 528, 132-136 (2015).

35. Kalekar, L. A. et al. CD4 $+\mathrm{T}$ cell anergy prevents autoimmunity and generates regulatory T cell precursors. Nat. Immunol. 17, 1-12 (2016).

36. Keck, S. et al. Antigen affinity and antigen dose exert distinct influences on CD4 T-cell differentiation. Proc. Natl Acad. Sci. 111, 14852-14857 (2014).

37. Fazilleau, N., McHeyzer-Williams, L. J., Rosen, H. \& McHeyzer-Williams, M. G. The function of follicular helper $\mathrm{T}$ cells is regulated by the strength of $\mathrm{T}$ cell antigen receptor binding. Nat. Immunol. 10, 375-384 (2009).

38. Waldmann, H., Lefkovits, I. \& Quintáns, J. Limiting dilution analysis of helper T-cell function. Immunology 28, 1135-1148 (1975). 
39. Schubert, D. A. et al. Self-reactive human CD4 T cell clones form unusual immunological synapses. J. Exp. Med. 209, 335-352 (2012).

40. Hong, J. et al. Force-Regulated In Situ TCR-Peptide-Bound MHC Class II Kinetics Determine Functions of CD4 + T Cells. J. Immunol. 195, 3557-3564 (2015).

41. Zhang, S.-Q. et al. Direct measurement of $\mathrm{T}$ cell receptor affinity and sequence from naïve antiviral T cells. Sci. Transl. Med. 8, 341ra77-341ra77 (2016).

42. Legoux, F. P. et al. CD4 + T cell tolerance to tissue-restricted self antigens is mediated by antigen-specific regulatory $\mathrm{t}$ cells rather than deletion. Immunity 43, 1-13 (2015).

43. Malhotra, D. et al. Tolerance is established in polyclonal CD4 $+\mathrm{T}$ cells by distinct mechanisms, according to self-peptide expression patterns. Nat. Immunol. 17, 187-195 (2016).

44. Whitmire, J. K. et al. Precursor frequency, nonlinear proliferation, and functional maturation of virus-specific CD4 + T Cells. J. Immunol. 176, 3028-3036 (2006).

45. Hataye, J., Moon, J. J., Khoruts, A., Reilly, C. \& Jenkins, M. K. Nave and memory CD4 $+\mathrm{T}$ cell survival controlled by clonal abundance. Science 312, 114-116 (2006).

46. Bachmann, M. et al. Developmental regulation of Lck targeting to the CD8 coreceptor controls signaling in naive and memory T cells. J. Exp. Med. 189, 1521-1530 (1999).

47. Buchholz, V. R. et al. Disparate individual fates compose robust CD8 $+\mathrm{T}$ cell immunity. Science 340, 630-635 (2013).

48. Gerlach, C. et al. Heterogeneous differentiation patterns of individual CD8 + T cells. Science 340, 635-639 (2013)

49. Hebeisen, M. et al. SHP-1 phosphatase activity counteracts increased T cell receptor affinity. J. Clin. Invest. 123, 1044-1065 (2013).

50. Merkenschlager, J. \& Kassiotis, G. Narrowing the gap: preserving repertoire diversity despite clonal selection during the $\mathrm{CD} 4 \mathrm{~T}$ cell response. Front. Immunol. 6, 1-11 (2015).

51. Huang, J. et al. Detection, phenotyping, and quantification of antigen-specific $T$ cells using a peptide-MHC dodecamer. Proc. Natl. Acad. Sci. 113, E1890-E1897 (2016).

52. Stone, J. D. \& Kranz, D. M. Role of T cell receptor affinity in the efficacy and specificity of adoptive T cell therapies. Front. Immunol. 4, 1-16 (2013).

53. Cameron, B. J. et al. Identification of a Titin-derived HLA-A1-presented peptide as a cross-reactive target for engineered MAGE A3-directed T cells. Sci. Transl. Med. 5, 197ra103 (2013).

54. Linette, G. P. et al. Cardiovascular toxicity and titin cross-reactivity of affinityenhanced T cells in myeloma and melanoma. Blood 122, 863-871 (2013).

55. Oestreich, K. J., Mohn, S. E. \& Weinmann, A. S. Molecular mechanisms that control the expression and activity of Bcl-6 in TH1 cells to regulate flexibility with a TFH-like gene profile. Nat. Immunol. 13, 405-411 (2012).

56. Pepper, M., Pagán, A. J., Igyártó, B. Z., Taylor, J. J. \& Jenkins, M. K. Opposing signals from the Bcl6 transcription factor and the interleukin-2 receptor generate $\mathrm{T}$ helper 1 central and effector memory cells. Immunity 35, 583-595 (2011).

57. van Panhuys, N., Klauschen, F. \& Germain, R. N. T-Cell-receptor-dependent signal intensity dominantly controls $\mathrm{CD} 4(+) \mathrm{T}$ cell polarization in vivo. Immunity 41, 1-12 (2014)

58. Knudson, K. M., Goplen, N. P., Cunningham, C. A., Daniels, M. A. \& Teixeiro, E. Low-Affinity $\mathrm{T}$ cells are programmed to maintain normal primary responses but are impaired in their recall to low-affinity ligands. Cell Rep. 4, 554-565 (2013).

59. Gottschalk, R. A., Corse, E. \& Allison, J. P. TCR ligand density and affinity determine peripheral induction of Foxp3 in vivo. J. Exp. Med. 207, 1701-1711 (2010).

60. Sauer, S. et al. T cell receptor signaling controls Foxp3 expression via PI3K, Akt, and mTOR. Proc. Natl Acad. Sci. USA 105, 7797-7802 (2008).

61. Mason, D. A very high level of crossreactivity is an essential feature of the T-cell receptor. Immunol. Today 19, 395-404 (1998).

62. Yager, E. J. et al. Age-associated decline in T cell repertoire diversity leads to holes in the repertoire and impaired immunity to influenza virus. J. Exp. Med. 205, 711-723 (2008).

63. Woodland, D. L., Kotzin, B. L. \& Palmer, E. Functional consequences of a T cell receptor D beta 2 and J beta 2 gene segment deletion. J. Immunol. 144, 379-385 (1990).
64. Messaoudi, I., Guevara Patiño, J. A., Dyall, R., LeMaoult, J. \& Nikolich-Zugich, J. Direct link between mhc polymorphism, T cell avidity, and diversity in immune defense. Science 298, 1797-1800 (2002).

65. Casrouge, A. et al. Size estimate of the alpha beta TCR repertoire of naive mouse splenocytes. J. Immunol. 164, 5782-5787 (2000).

66. Liñares, D. et al. The magnitude and encephalogenic potential of autoimmune response to MOG is enhanced in MOG deficient mice. J. Autoimmun. 21, 339-351 (2003).

67. Moon, J. J. et al. Tracking epitope-specific T cells. Nat. Protoc. 4, 565-581 (2009).

68. Dash, P. et al. Paired analysis of TCR $\alpha$ and TCR $\beta$ chains at the single-cell level in mice. J. Clin. Invest. 121, 288-295 (2011).

69. Lefranc, M.-P. IMGT-ONTOLOGY and IMGT databases, tools and Web resources for immunogenetics and immunoinformatics. Mol. Immunol. 40, 647-660 (2004).

70. Lefranc, M.-P. et al. IMGT-ONTOLOGY for immunogenetics and immunoinformatics. In Silico Biol. 4, 17-29 (2004).

71. Lefranc, M.-P. IMGT, the International ImMunoGeneTics Information System for Immunoinformatics: methods for querying IMGT databases, tools, and web resources in the context of immunoinformatics. Mol. Biotechnol. 40, 101-111 (2008).

72. McMaster, S. R., Wilson, J. J., Wang, H. \& Kohlmeier, J. E. Airway-resident memory CD8 $\mathrm{T}$ cells provide antigen-specific protection against respiratory virus challenge through rapid IFN- $\gamma$ production. J. Immunol. 195, 203-209 (2015).

73. Rosenbloom, D. I. S. et al. Designing and interpreting limiting dilution assays: general principles and applications to the latent reservoir for HIV-1 Daniel. Open Forum Infect. Dis. 2, ofv123 (2015).

\section{Acknowledgements}

This work was supported by NIH grant T32 AI007610, RO1 AI096879, RO1 AI110113, R01 NS071518 and F31 NS086130. Laurel Lawrence maintained the mice used in these experiments and we would like to thank the Evavold Lab, Marc Jenkins, Rustom Antia, Veronika Zarnitsyna and Emily Cartwright for helpful discussion.

\section{Author contributions}

R.J.M. designed, performed and analysed experiments and wrote manuscript. R.A. performed experiment and discussed findings. H.A.M. performed experiments. B.D.E. designed experiments, discussed findings and wrote manuscript.

\section{Additional information}

Supplementary Information accompanies this paper at http://www.nature.com/ naturecommunications

Competing financial interests: The authors declare no competing financial interests.

Reprints and permission information is available online at http://npg.nature.com/ reprintsandpermissions/

How to cite this article: Martinez, R. J. et al. Low-affinity CD4 + T cells are major responders in the primary immune response. Nat. Commun. 7, 13848 doi: 10.1038/ncomms13848 (2016)

Publisher's note: Springer Nature remains neutral with regard to jurisdictional claims in published maps and institutional affiliations.

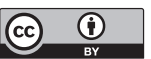

This work is licensed under a Creative Commons Attribution 4.0 International License. The images or other third party material in this article are included in the article's Creative Commons license, unless indicated otherwise in the credit line; if the material is not included under the Creative Commons license, users will need to obtain permission from the license holder to reproduce the material. To view a copy of this license, visit http://creativecommons.org/licenses/by/4.0/

(C) The Author(s) 2016 